\section{Direct Shoot Organogenesis in Murraya paniculata (L.) Jack: A Prerequisite for Genetic Transformation}

\author{
Xiuli Shen ${ }^{1}$, Vladimir Orbović, Manjul Dutt, William S. Castle, \\ and Frederick G. Gmitter, Jr. \\ Citrus Research and Education Center (CREC), Institute of Food and \\ Agricultural Science (IFAS), University of Florida (UF), 700 Experiment \\ Station Road, Lake Alfred, FL 33850-2299
}

Additional index words. direct shoot organogenesis, explant types, Murraya paniculata, plant growth regulators

\begin{abstract}
An efficient in vitro regeneration system through direct shoot organogenesis was established for Murraya paniculata (L.) Jack (Orange Jessamine). Epicotyls, leaves, roots, and cotyledons from in vitro-germinated seedlings and several plant growth regulators (PGRs) were evaluated for their effects on plant regeneration. Longitudinally cut epicotyl segments were observed to be the optimal explants followed by uncut epicotyls (not longitudinally cut). Roots, leaves, and cotyledons were not suitable as explants as a result of little or no shoot induction. Adventitious shoot induction was enhanced by the addition of 6-benzyladenine (BA). The highest percentage of shoot induction $(87 \%)$ and the greatest number of shoots per explant (12.7) occurred on Murashige and Skoog (MS) medium supplemented with $15 \mu \mathrm{M}$ BA from longitudinally cut epicotyls followed by 5.2 shoots per explant from uncut epicotyls. Optimal concentration of gibberellic acid $\left(\mathrm{GA}_{3}\right)$ for shoot elongation was observed to be $15 \mu \mathrm{M}$. Eighty-five percent of the regenerated shoots produced roots with an average of three roots per shoot on MS medium supplemented with $5 \mu M$ indole-3-butyric acid (IBA). Our protocol for direct shoot organogenesis can potentially lead to the development of a robust method for production of transgenic plants of $M$. paniculata through Agrobacteriummediated genetic transformation.
\end{abstract}

Orange Jessamine [Murraya paniculata (L.) Jack], a member of the Rutaceae family, is an attractive tropical evergreen plant (Gilman, 1999). It is also a preferred host of the Asian citrus psyllid (ACP), which transmits Candidatus Liberibacter asiaticus, the presumed pathogen that causes Huanglongbing (HLB), the most devastating disease in citrus (Halbert and Manjunath, 2004). Genetic transformation of $M$. paniculata with genes encoding insecticidal products that are deadly on ingestion by ACP could be a way to decrease its population, thus aiding citrus HLB management. One of the prerequisites of successful Agrobacterium-mediated genetic transformation is an efficient in vitro regeneration. Compared with other plant species, very little has been done on in vitro manipulation and regeneration of plants of M. paniculata. There are a few reports on in vitro culturing of $M$. paniculata. Jumin and Ahmad (1999) reported in vitro flowering of M. paniculata shoots derived from seed. Jumin and Nito (1996) observed induction of vegetative shoots from the epicotyls of seedlings in their study on in vitro flowering of orange Jessamine; however, they only reported percentage of shoot induction but

Received for publication 27 Mar. 2013. Accepted for publication 22 May 2013.

${ }^{1}$ To whom reprint requests should be addressed; e-maillili465@gmail.com. for easy removal and to improve seed germination. Seed coats were removed under sterile conditions and the seeds without seedcoats (Fig. 1B) were cultured individually in $25 \mathrm{~mm} \times 150$-mm glass test tubes containing $\approx 20 \mathrm{~mL}$ medium. Seed germination medium contained MS (Murashige and Skoog, 1962) mineral salts and vitamins supplemented with $0.5 \mathrm{~g} \cdot \mathrm{L}^{-1}$ malt extract, $25 \mathrm{mg} \cdot \mathrm{L}^{-1}$ adenine, and $25 \mathrm{~g} \cdot \mathrm{L}^{-1}$ sucrose. The tubes were kept in the dark in a growth chamber at a temperature of $22^{\circ} \mathrm{C}$ for 3 weeks and then transferred to the light condition under a 12-h photoperiod with a light intensity of $40 \mu \mathrm{mol} \cdot \mathrm{m}^{-2} \cdot \mathrm{s}^{-1}$ provided by cool white fluorescent lamps for another 2 weeks. Germinated seedlings were used as source of explants for shoot regeneration.

Direct shoot organogenesis. Epicotyls, roots, leaves, and cotyledons from germinated seedlings were tested for their ability to regenerate shoots in vitro. Epicotyls were cut into $10-\mathrm{mm}$ long segments and then half of them were cut longitudinally into two halves. Root explants were prepared by removing lateral roots first, and then main roots were cut transversely into $10-\mathrm{mm}$ long segments. Segments of epicotyls and roots were placed horizontally on the medium. For longitudinally cut epicotyls, the cut surface was placed facing down. Leaf and cotyledon margins were removed first, then blades containing the main vein were cut into $5 \mathrm{~mm} \times 5-\mathrm{mm}$ sections with additional two cuts across main vein and cultured with the abaxial surface in contact with the medium. Explants were cultured on MS medium supplemented with $0,5,15,30 \mu \mathrm{MBA}$. Explants were cultured in $100 \mathrm{~mm} \times 15-\mathrm{mm}$ sterile petri plates containing $20 \mathrm{~mL}$ of media. Ten explants were placed into each petri plate with four replicates per treatment. The number of explants with shoots and the number of shoots formed per explant were scored at the end of 4 weeks culture. Direct shoot induction percentage was calculated as the percentage of explants forming shoots.

Shoot elongation. Shoots that were $\approx 5 \mathrm{~mm}$ in length were excised and transferred to Magenta GA-7 vessels containing $50 \mathrm{~mL}$ MS medium supplemented with $0,5,15$, or $30 \mu \mathrm{M} \mathrm{GA}$. Four shoots were cultured per vessel, with 10 replicates per treatment. The length of each shoot was scored at the end of 4 weeks culture.

Root formation. Elongated shoots $\approx 20 \mathrm{~mm}$ in length were cultured in Magenta GA-7 vessels containing $50 \mathrm{~mL}$ MS supplemented with $0,5,15$, or $30 \mu \mathrm{M}$ IBA. Four shoots were cultured per vessel with 10 replicates per treatment. The number of shoots forming roots and the number of roots on each shoot were recorded at the end of 4 weeks culture.

General culture media and culture condition. The basal medium used for direct shoot organogenesis, shoot elongation, and root formation contained MS mineral salts, vitamins, and $25 \mathrm{~g} \cdot \mathrm{L}^{-1}$ sucrose. Culture media were adjusted to $\mathrm{pH}$ of 5.8 and solidified with $4 \mathrm{~g} \cdot \mathrm{L}^{-1}$ agar. Cultures were maintained in the 

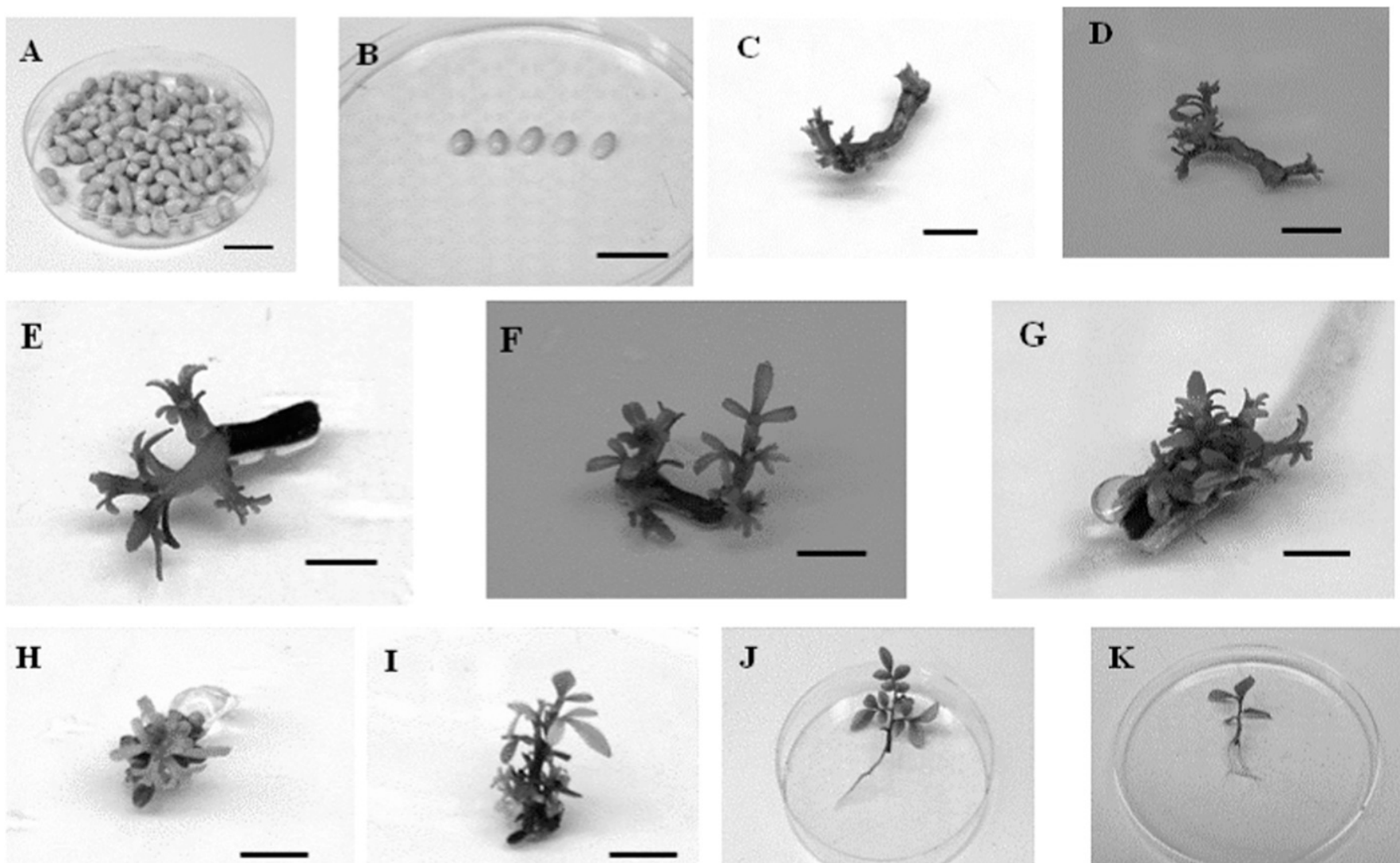

I

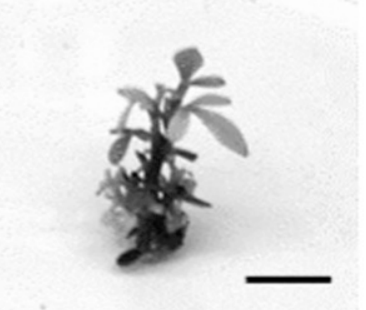

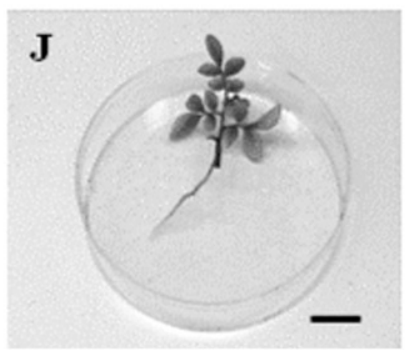

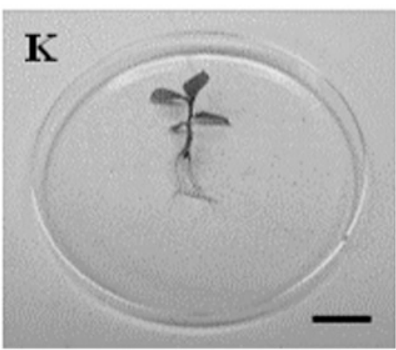

Fig. 1. (A) M. paniculata seeds with seedcoats. (B) M. paniculata seeds without seedcoats. (C) Shoot bud sprouting at both ends of uncut epicotyls of M. paniculata within 2 weeks culture. (D) Shoot development at both ends of uncut epicotyls of M. paniculata by 4 weeks culture. (E) Multiple shoots formation at one end longitudinally cut epicotyls of M. paniculata. (F) Multiple shoots formation at both ends of longitudinally cut epicotyls. (G) Multiple shoots formation along both sides longitudinally cut epicotyls. (H) Dwarf shoots derived from longitudinally cut epicotyls. (I) Elongated shoots on Murashige and Skoog (MS) supplemented with $15 \mu \mathrm{M}$ gibberellic acid $\left(\mathrm{GA}_{3}\right)$. (J) Single root formation at the base of the shoot. (K) Multiple root formation at the base of the shoot. Bars $=5 \mathrm{~mm}$.

culture room at a temperature of $22{ }^{\circ} \mathrm{C}$ under a 12-h light photoperiod with a light intensity of $40 \mu \mathrm{mol} \cdot \mathrm{m}^{-2} \cdot \mathrm{s}^{-1}$ provided by cool white fluorescent lamps.

Statistical analysis. Experiments were conducted using a completely randomized design. Data were subject to analysis of variance using SAS (SAS Institute Inc., 1999). Mean separation was achieved by least significant difference test at the $95 \%$ level.

\section{Results and Discussion}

A protocol for induction of direct shoot organogenesis in M. paniculata is established in this study. This protocol will be used to facilitate the effort of successful genetic transformation in this species.

The types of explants used for in vitro regeneration of $M$. paniculata greatly affected the regeneration efficiency. Root explants failed to produce any shoot (data not shown). Only one of 40 cotyledon explants produced a single shoot, and one of 40 leaf explants produced multiple shoots around the cut vein. Therefore, these types of explants are not suitable for direct shoot organogenesis in $M$. paniculata. The most responsive explants were longitudinally cut epicotyl segments followed by uncut epicotyls (Table 1). These results are consistent with other reports regarding the influence of explant type on in vitro regeneration efficiency. Yang et al. (2006) found that kumquat (Fortunella crassifolia Swingle) epicotyl segments have the strongest regeneration potency followed by hypocotyl segments, but no shoots could be regenerated from cotyledons. A significant effect of longitudinal sectioning of explants was observed on shoot organogenesis in Ponkan mandarin (Citrus reticulata Blanco) by Zeng et al. (2009). When compared with epicotyls that were not cut longitudinally, shoot regeneration efficiency of cut epicotyls was much higher $(25.3 \%$ vs. $72.5 \%$ ). The average number of shoots per explant also improved from 1.6 to 7.8 when epicotyls were cut longitudinally. Yu et al. (2002) reported that both plant regeneration and transformation efficiency were increased by using longitudinally cut epicotyls compared with uncut epicotyls in sweet orange and Carrizo citrange.

Uncut epicotyl explants remained green on the culture medium. Small, green, nodular protuberances were initially observed at the cut ends. These protuberances subsequently gave rise to shoots (Fig. 1C). Single or multiple adventitious shoots were produced from both ends by the end of 4 weeks in culture (Fig. 1D). Similarly, shoots developed at one end (Fig. 1E), both ends (Fig. 1F), or along the sides (Fig. 1G) on longitudinally cut epicotyl explants.

Plant growth regulators are another factor affecting in vitro generation. BA, the most commonly used cytokinin, has been shown to stimulate adventitious shoot induction in a broad range of plant species (Burns et al., 2012; Ghimire et al., 2012; Shaik et al., 2011; Song et al., 2011). The current study also demonstrated that BA is essential for direct shoot induction of M. panniculata (Table 1). On MS medium without BA, the percentage of shoot induction was low $(7.5 \%)$ with a low average number of 0.1 shoots per uncut epicotyl explant. The percentage of direct shoot induction from longitudinally cut epicotyls cultured on MS medium without BA was $52 \%$ and the average number of shoots per explant was 0.6. Percentages of direct shoots induced were not significantly different between longitudinally cut and uncut epicotyls cultured on MS supplemented with $\mathrm{BA}$ at 5,15 , or $30 \mu \mathrm{M}$. However, shoot number was significantly higher on longitudinally cut epicotyls compared with uncut epicotyls cultured on MS medium with 15 $\mu \mathrm{M}$ BA with 12.7 shoots per explant vs. 5.2 
Table 1. Effect of 6-benzyladenine (BA) concentrations on induction of direct shoot regeneration from two types of epicotyl explants of M. paniculata.

\begin{tabular}{lccc}
\hline Explant types & $\mathrm{BA}(\mu \mathrm{M})$ & $\begin{array}{c}\text { Direct shoot } \\
\text { induction }(\%)^{\mathrm{z}}\end{array}$ & $\begin{array}{c}\text { Avg number } \\
\text { of shoots/explant }\end{array}$ \\
\hline Epicotyls & 0 & $7.5 \mathrm{c}$ & $0.1 \mathrm{e}$ \\
& 5 & $75 \mathrm{a}$ & $1.4 \mathrm{~d}$ \\
Longitudinally & 15 & $88 \mathrm{a}$ & $5.2 \mathrm{~b}$ \\
cut epicotyls & 30 & $78 \mathrm{a}$ & $2.5 \mathrm{~d}$ \\
& 0 & $52 \mathrm{~b}$ & $0.6 \mathrm{de}$ \\
& 5 & $73 \mathrm{a}$ & $4.0 \mathrm{c}$ \\
& 15 & $87 \mathrm{a}$ & $12.7 \mathrm{a}$ \\
& 30 & $78 \mathrm{a}$ & $5.8 \mathrm{~b}$ \\
\hline
\end{tabular}

z,y Means followed by the same letter in each column are not significantly different at 0.05 level. Data represent means of four replicates, 10 samples per replicate.

Table 2. Effect of gibberllic acid $\left(\mathrm{GA}_{3}\right)$ concentrations on M. paniculata shoot elongation.

\begin{tabular}{cc}
\hline $\mathrm{GA}_{3}(\mu \mathrm{M})$ & Shoot length $(\mathrm{mm})^{2}$ \\
\hline 0 & $12 \mathrm{~d}$ \\
5 & $23 \mathrm{c}$ \\
15 & $58 \mathrm{a}$ \\
30 & $37 \mathrm{~b}$ \\
\hline
\end{tabular}

${ }^{\mathrm{z}}$ Means followed by the same letter in each column are not significantly different at 0.05 level. Data represent means of 10 replicates, four samples per replicate.

Table 3. Effect of indole-3-butyric acid (IBA) concentrations on root formation of $M$. paniculata shoots.

\begin{tabular}{ccc}
\hline IBA $(\mu \mathrm{M})$ & $\begin{array}{c}\text { Root } \\
\text { formation }(\%)^{\mathrm{z}}\end{array}$ & $\begin{array}{c}\text { Mean number } \\
\text { of roots/shoot }\end{array}$ \\
\hline 0 & $0 \mathrm{~d}$ & $0 \mathrm{c}$ \\
5 & $85 \mathrm{a}$ & $3.0 \mathrm{a}$ \\
15 & $55 \mathrm{~b}$ & $1.6 \mathrm{~b}$ \\
30 & $40 \mathrm{c}$ & $1.2 \mathrm{~b}$ \\
\hline
\end{tabular}

${ }^{z, y}$ Means followed by the same letter in each column are not significantly different at 0.05 level. Data represent means of 10 replicates, four samples per replicate.

shoots, respectively (Table 1). Rout (2005) found that BA was effective in shoot bud induction from stem segments of Murraya koenigii Koenig. No shoot buds could be induced on medium without BA; BA at $2.4 \mathrm{mg} \cdot \mathrm{L}^{-1}$ gave the highest shoot induction percentage $(82.2 \%)$ and average number of 6.85 shoots per explant. In the current study, the optimal BA concentration that yielded the highest shoot induction percentage and the greatest number of shoots per explant was $15 \mu \mathrm{M}$. The difference in the optimal BA concentrations required for shoot induction in $M$. koenigii and $M$. paniculata may be a consequence of the different genetic backgrounds of these two plant species.

Elongation stages are optional in in vitro regeneration. However, in our case, the production of shoots shorter than $5 \mathrm{~mm}$ (Fig. 1H) made their elongation necessary. Rani et al. (2010a) also found that multiple shoots of $M$. koenigii produced on MS medium supplemented with $2.5 \mathrm{mg} \cdot \mathrm{L}^{-1}$ BAP were dwarfed. In our study, although shoots could be elongated on MS basal medium without $\mathrm{GA}_{3}$, incorporating $\mathrm{GA}_{3}$ in culture medium significantly increased shoot length (Fig. 1I). Shoot length was increased to average values of
$23 \mathrm{~mm}, 58 \mathrm{~mm}$, and $37 \mathrm{~mm}$ by 5,15 , and $30 \mu \mathrm{M} \mathrm{GA}_{3}$, respectively (Table 2 ). Bhuyan et al. (1997) also reported that $\mathrm{GA}_{3}$ stimulated shoot elongation in the study of micropropagation of $M$. koenigii.

Unlike many other woody species for which rooting is a significant obstacle for in vitro propagation (De Klerk, 2002; Marks and Simpson, 2000), in vitro-developed M. paniculata shoots easily rooted on MS medium supplemented with IBA. No root formation was observed on shoots incubated on MS medium without IBA. IBA significantly promoted root formation at all concentrations tested. Single roots (Fig. 1J) or multiple roots (Fig. 1K) could be obtained on medium containing IBA by the end of 4 weeks culture. At $5 \mu \mathrm{M}$ IBA, $85 \%$ of the shoots formed roots with an average of three roots per shoot (Table 3). Rani et al. (2010b) reported that among the auxins tried, IBA $\left(1.5 \mathrm{mg} \cdot \mathrm{L}^{-1}\right)$ produced the highest rooting percentage $(80 \%)$ and the longest roots $(3.34 \mathrm{~cm})$ in $M$. koenigii. A stimulating effect of IBA on rooting of $M$. koenigii was also reported by Bhuyan et al. (1997), Lalitha et al. (1997), and Rani et al. (2010a).

\section{Conclusions}

An efficient protocol through direct shoot organogenesis from epicotyls of in vitrogerminated seedlings of $M$. paniculata has been described here. This study demonstrated that explant types and PGRs are major factors affecting the efficiency of direct shoot organogenesis. Shoot induction, shoot elongation, and root formation can be optimized by manipulation of PGRs in culture media. This protocol will be used for development of a genetic transformation system for $M$. paniculata to attempt development of ACP-lethal clones to support the management of HLB.

\section{Literature Cited}

Bhuyan, A.K., S. Pattnaik, and P.K. Chand. 1997. Micropropagation of curry leaf tree [Murraya koenigii (L.) Spreng.] by axillary proliferation using intact seedlings. Plant Cell Rep. 16:779782.

Burns, S.P., M. Gallo, and B.B. Tillman. 2012. Expansion of a direct shoot organogenesis system in peanut (Arachis hypogaea L.) to include US cultivars. In Vitro Cell. Dev. Biol. Plant 48:58-66.
De Klerk, G.J. 2002. Rooting of microcuttings: Theory and practice. In Vitro Cell. Dev. Biol. Plant 38:415-422.

Dutt, M., and J.W. Grosser. 2009. Evaluation of parameters affecting Agrobacterium-mediated transformation of citrus. Plant Cell Tissue Organ Cult. 98:331-340.

Dutt, M., M. Vasconcellos, and J.W. Grosser. 2011 Effects of antioxidants on Agrobacteriummediated transformation and accelerated production of transgenic plants of Mexican lime (Citrus aurantifolia Swingle). Plant Cell Tissue Organ Cult. 107:79-89.

Ghimire, B.K., C.Y. Yu, and I.M. Chung. 2012 Direct shoot organogenesis and assessment of genetic stability in regenerants of Solanum aculeatissimum Jacq. Plant Cell Tissue Organ Cult. 108:455-464.

Gilman, E.F. 1999. Murraya paniculata. FPS-416. Cooperative Extension Service, Institute of Food and Agricultural Science, University of Florida, FL.

Halbert, S.E. and K.L. Manjunath. 2004. Asian citrus psyllids (Sternorrhyncha:Psyllidae) and greening disease of citrus: A literature review and assessment of risk in Florida. Fla. Entomol. 87:330-353.

Jumin, H.B. and M. Ahmad. 1999. High-frequency in vitro flowering of Murraya paniculata (L.) Jack. Plant Cell Rpt. 18:764-768.

Jumin, H.B. and N. Nito. 1996. In vitro flowering of orange jessamine [Murraya paniculata (L.) Jack]. Experientia 52:268-272.

Lalitha, S., S. Thamburaj, M. Vijayakamar, and T. Thangaraj. 1997. A note on the effect of IBA on rooting of curry leaf cuttings. South Indian Hort. 45:202.

Ling, J.T. and M. Iwamasa. 1997. Plant regeneration from embryogenic calli of six Citrus related genera. Plant Cell Tissue Organ Cult. 49:145-148.

Marks, T.R. and S.E. Simpson. 2000. Interaction of explant type and indole-3-butyric acid during rooting in vitro in a range of difficult and easyto-root woody plants. Plant Cell Tissue Organ Cult. 62:65-74.

Murashige, T. and F. Skoog. 1962. A revised medium for rapid growth and bioassay with tobacco tissue culture. Physiol. Plant. 15:473495.

Orbović, V. and J.W. Grosser. 2006. Citrus: Sweet orange (Citrus sinensis L. Osbeck 'Valencia') and carrizo citrange [Citrus sinensis (L.) Osbeck $\times$ Poncirus trifoliata (L.) Raf.], p. 177-189. In: Wang, K. (ed.). Agrobacterium protocol-Methods in molecular biology. Humana Press Inc., Totowa, NJ.

Rani, U., M.M. Sharma, N. Ismail, and A. Batra. 2010a. Quick in vitro plant regeneration from immature seeds of Murraya koenigii (L.). Spreng. Acad. J. Plant Sci. 3:19-22.

Rani, U., N. Ismail, G. Zibbu, and A. Batra. 2010b. High frequency shoots regeneration from in vitro raised seedlings of Murraya Koenigii (L.) Spreng. Intl. J. Pharma. Bio. Sci. 1:1-7.

Rout, G.R. 2005. Direct plant regeneration of curry leaf tree (Murraya koenigii Koenig.), an aromatic plant. In Vitro Cell. Dev. Biol. Plant. 41:133-136.

SAS Institute Inc. 1999. Version 8.02. SAS Institute, Cary, NC.

Shaik, S., N. Singh, and A. Nicholas. 2011. Cytokinin-induced organogenesis in Lessertia (Sutherlandia) frutescens L. using hypocotyl and cotyledon explants affects yields of L-canavanine in shoots. Plant Cell Tissue Organ Cult. 105:439-446. 
Song, J.Y., N.S. Mattson, and B.R. Jeong. 2011. Efficiency of shoot regeneration from leaf, stem petiole and petal explants of six cultivars of Chrysanthemum morifolium. Plant Cell Tissue Organ Cult. 107:295-304.

Taha, R.M. and N.W. Haron. 2008. Some morphological and anatomical studies of leaves and flowers of Murraya paniculata (Jack)
Linn. in vivo and in vitro. Pak. J. Biol. Sci. 11: 1021-1026.

Yang, L., C.J. Xu, G.B. Hu, and K.S. Chen. 2006. Direct shoot organogenesis and plant regeneration in Fortunella crassifolia. Biol. Plant 50:729-732.

Yu, C., S. Huang, C. Chen, Z. Deng, P. Ling, and F.G. Gmitter. 2002. Factors affecting
Agrobacterium-mediated transformation and regeneration of sweet orange and citrange. Plant Cell Tissue Organ Cult. 71:147-155.

Zeng, L., H. Xu, Y. Zeng, A. Luan, and H. Wang. 2009. High efficiency in vitro plant regeneration from epicotyl explants of Ponkan mandarin (Citrus reticulata Blanco). In Vitro Cell. Dev. Biol. Plant 45:559-564. 